\title{
Use of pocket computers for self-administration of cognitive tests in the field
}

\author{
RICHARD POPPER, HEATHER DRAGSBAEK, STEPHEN F. SIEGEL, and EDWARD HIRSCH \\ U.S. Army Natick Research, Development and Engineering Center, Natick, Massachusetts
}

\begin{abstract}
A pocket computer is described that can be used by subjects to self-administer cognitive tests in field situations. Two cognitive tests, a vigilance and an encoding task, were developed for this computer and used to test cognitive performance during a 30-day military field exercise.
\end{abstract}

To assess the cognitive performance of soldiers during a prolonged (30-day) combat exercise, portable equipment was needed for administering tests in the field. The need to administer performance tests outside the laboratory has resulted in the development of specialized test devices, such as portable reaction time recorders (Wilkinson \& Houghton, 1975, 1982) and computer software for running cognitive tests on portable microcomputers (Bittner, Smith, Kennedy, Staley, \& Harbeson, 1985; Drury, 1987; Schlichting \& Wray, 1986).

The selection of portable test equipment for the 30-day field test was guided by several considerations. The length and nature of the training exercise precluded frequent (i.e., daily) access by experimenters for administering tests to troops. At the same time, frequent testing, conducted under actual field conditions, was considered desirable so that variations in performance over the test period could be tracked. Although these test conditions constituted a substantial challenge, they are not unique in applied research, where access to subjects and opportunities for testing in realistic environments can be limited for a variety of practical reasons.

\section{A POCKET COMPUTER SYSTEM}

Pocket computers have potentially wide application in field research. They weigh only 1-2 lbs (450-900 g) and are about the size of a large calculator. In comparison, laptop computers are several times that size and weight. Although not as powerful in some respects as laptop computers, pocket computers can, in many cases, meet the memory, programming, and timing requirements for computer-based administrations of performance tests. In addition to being portable, some models of pocket computers also have the advantage of low cost. This makes it feasible to issue several machines to subjects for use

Funds for this research were provided by the Military Nutrition Division of the U.S. Army Research Institute of Environmental Medicine. The authors wish to thank David D. Schnakenberg and E. W. Askew for their support of the project. Stephen F. Siegel is now at Applied Intelligence Systems, Inc., New York, NY 10001. Reprint requests should be sent to Richard Popper, U.S. Army Natick Research, Development and Engineering Center, Natick, MA 01760-5020. in the field, possibly equipping each subject with his/her own personal test device. The availability of multiple computers in the field greatly reduces the administrative burden of scheduling multiple subjects for testing on one or on a small number of computers, permits greater control over the time of day testing is conducted (several subjects can be tested at the same time), and allows complete independence among subjects who do not need to be tested on the same device.

A market survey of pocket computers identified a number of devices, some of which are listed in Table 1. The Melard Access, Panasonic Personal Partner, and MSI PDT III offer large memory and other powerful features at a cost of approximately $\$ 1,000$ per unit. The Melard and Panasonic computers provide an eight-line display, located in a flip-up cover, whereas the MSI PDT III has only two lines; however, the construction of the MSI is more rugged. Applications for all three devices must be developed on an IBM PC-compatible microcomputer, using separately purchased software development tools, and then must be downloaded. For the Panasonic unit, a "pocket DOS" operating system (available from Pocket Soft, Houston, TX) allows programs written in Microsoft C or QuickBASIC to run from an EPROM.

Much more moderately priced are the products by Sharp (approximately $\$ 200$ per unit, with built-in BASIC). Although the Sharp PC-1350 has a larger display than the PC-1500A, the latter has an internal clock and can be connected to an RS232 interface. More recently, Sharp has introduced the PC-1600, which offers more memory than the PC-1500A, a four-line display, an external portable floppy disk drive, and the facility for running programs from EPROM.

On the basis of a number of criteria, including cost, programming features, and size of memory, we selected the Sharp PC-1500A. Because the intention was to have subjects repeatedly self-administer tests in the field, it was necessary to retain the results of each test, preferably without the need for external mass storage devices, until such a time that the experimenter could print out or transfer the data. This facility was provided by the PC-1500A's AUTO RUN statement. A BASIC program with AUTO RUN as the first statement is started automatically upon power-on. AUTO RUN, unlike RUN, prevents the ini- 
Table 1

Specifications of Five Pocket Computers

\begin{tabular}{|c|c|c|c|c|c|}
\hline Manufacturer & $\begin{array}{l}\text { Melard Technologies } \\
\text { Elmsford, NY }\end{array}$ & $\begin{array}{l}\text { Panasonic } \\
\text { Secaucus, NJ }\end{array}$ & $\begin{array}{l}\text { MSI Data Corp. } \\
\text { Costa Mesa, CA }\end{array}$ & $\begin{array}{l}\text { Sharp Electronics } \\
\text { Paramus, NJ }\end{array}$ & $\begin{array}{l}\text { Sharp Electronics } \\
\text { Paramus, NJ }\end{array}$ \\
\hline Device & Access & Personal Partner & PDT III & PC-1350 & PC-1500A \\
\hline Memory & $\begin{array}{l}\text { RAM: } 56 \mathrm{~K}+64 \mathrm{~K} \text { or } \\
512 \mathrm{~K} \text { RAM cartridge }\end{array}$ & $\begin{array}{l}\text { RAM: } 8 \mathrm{~K} \text {, } \\
\text { expandable to } 128 \mathrm{~K} \\
\text { w/ RAM board } \\
\text { ROM: } 64 \mathrm{~K} \text {, w/ EPROM } \\
\text { up to } 256 \mathrm{~K}\end{array}$ & $\begin{array}{l}\text { RAM: } 16 \mathrm{~K} \text {, } \\
\text { expandable to } 256 \mathrm{~K} \\
\text { ROM: } 32 \mathrm{~K} \text { plus } 16 \mathrm{~K} \\
\text { or } 32 \mathrm{~K} \text { EPROM }\end{array}$ & $\begin{array}{l}\text { RAM: } 5 \mathrm{~K} \text {, } \\
\text { expandable to } 21 \mathrm{~K} \\
\text { w/ RAM cards } \\
\text { ROM: } 40 \mathrm{~K}\end{array}$ & $\begin{array}{l}\text { RAM: } 8.5 \mathrm{~K} \text {, } \\
\text { expandable to } 24.5 \mathrm{~K} \\
\text { using memory module } \\
\text { ROM: } 16 \mathrm{~K}\end{array}$ \\
\hline Dimensions & $216 \times 95 \times 44 \mathrm{~mm}$ & $258 \times 110 \times 41 \mathrm{~mm}$ & $170 \times 96.5 \times 33 \mathrm{~mm}$ & $182 \times 72 \times 16 \mathrm{~mm}$ & $195 \times 86 \times 25.5 \mathrm{~mm}$ \\
\hline Weight & $672 \mathrm{~g}$ & $890 \mathrm{~g}$ & $510 \mathrm{~g}$ & $205 \mathrm{~g}$ & $375 \mathrm{~g}$ \\
\hline Language & C/Assembly & Forth/Assembly & BASIC/Assembly & BASIC/Assembly & BASIC/Assembly \\
\hline Display & $\begin{array}{l}8 \text { line } \times 40 \text { char } \\
64 \times 256 \text { dots } L C D\end{array}$ & $\begin{array}{l}8 \text { line } \times 80 \text { char } \\
64 \times 480 \text { dots } L C D\end{array}$ & $\begin{array}{l}2 \text { line } \times 32 \text { char } \\
\text { LCD }\end{array}$ & $\begin{array}{l}4 \text { line } \times 24 \text { char } \\
32 \times 150 \text { dots } L C D\end{array}$ & $\begin{array}{l}1 \text { line } \times 26 \text { char } \\
7 \times 156 \text { dots } L C D\end{array}$ \\
\hline Power & $\begin{array}{l}\text { Lithium cell } \\
(12 \mathrm{~h})\end{array}$ & $\begin{array}{l}\text { NiCd rechargeable } \\
\text { battery }\end{array}$ & $\begin{array}{l}4 \text { AA batteries } \\
(100 \mathrm{~h})\end{array}$ & $\begin{array}{l}2 \text { Lithium cell } \\
(250 \mathrm{~h})\end{array}$ & $\begin{array}{l}4 \mathrm{AA} \text { batteries } \\
(50 \mathrm{~h})\end{array}$ \\
\hline Options/Interfaces & $\begin{array}{l}\text { Internal modem, } \\
\text { RS-232C }\end{array}$ & $\begin{array}{l}\text { Internal modem, } \\
\text { portable printer, } \\
\text { RS-232C }\end{array}$ & $\begin{array}{l}\text { Internal modem, op- } \\
\text { tical wand, portable } \\
\text { printer, RS-232C }\end{array}$ & $\begin{array}{l}\text { Cassette, portable } \\
\text { color printer }\end{array}$ & $\begin{array}{l}\text { Cassette, portable } \\
\text { color printer, } \\
\text { RS-232C }\end{array}$ \\
\hline
\end{tabular}

tialization of variables and arrays upon the start of the program, leaving the memory contents unchanged from the previous time the program was executed. Provided that the program is written so that existing data are not overwritten, it is possible for a subject to run tests repeatedly, turning the computer on and off as required, while preserving the data from each run of the program in memory for eventual printing or uploading by the experimenter.

Another useful feature of the PC-1500A's BASIC is the LOCK statement. Included within a program, this statement prevents the subject from being able to list a program and to inadvertently change program lines or the memory contents of any variables. Such safeguards are important when subjects are given control of the testing device for prolonged periods of time.

To protect the computer against impact damage during transport and exposure to dirt and rain, a two-piece plastic case was fabricated and lined with shock-absorbent material. In addition, the computer was vacuum-sealed in transparent plastic using a household "seal-a-bag" device. The thin plastic material adhered closely to the computer and did not interfere with operating the keyboard.

\section{COGNITIVE TESTS}

\section{General Description}

Two cognitive tasks, a vigilance task and an encoding task, were developed and tested on the pocket computer.

Vigilance task. The vigilance task is a modified version of a task described by Bakan (1959). A series of single digits is flashed on the screen, and the subject's task is to detect target sequences. A target sequence is defined as an odd digit, followed by an even digit, followed by an odd digit, where the two odd digits are different. For example, the sequence " 361 " is a target, but the se- quence " 363 " is not. The latter type of sequence is called a "distractor." Digits are presented in a continuous stream, and the subject depresses a key to indicate the presence of a target. The experimenter controls the number and rate of digits presented and the average number of targets and distractors; the exact number and temporal distribution of targets and distractors is determined randomly. Summary statistics for each session include the number of correct detections, the number of misses, the number of distractor hits (the number of times the subject incorrectly identifies a distractor as a target), and the number of other errors. All statistics are computed separately for the first, the middle, and the last third of each session. Additional indices of performance can be calculated manually from these statistics based on the theory of signal detection (Davies \& Parasuraman, 1282; Green \& Swets, 1966).

Encoding task. The encoding task is a simulation of a military communications task and is illustrated in Figure 1. Subjects are asked to encode a series of five-

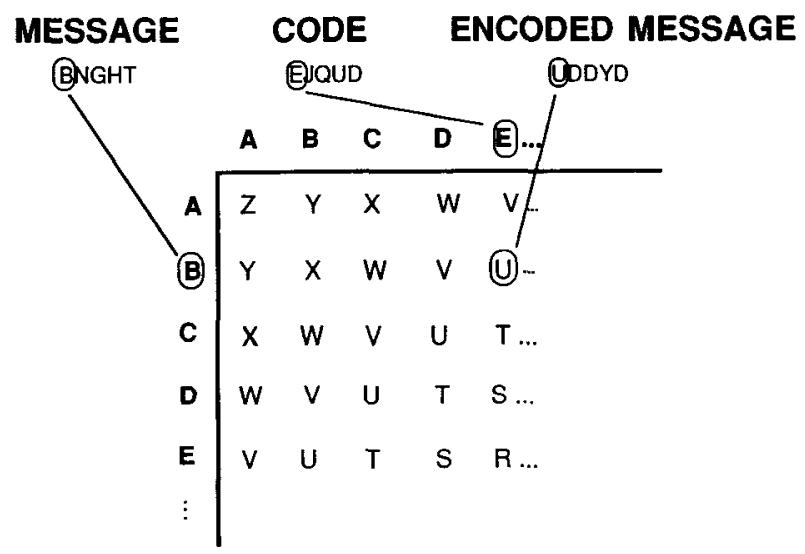

Figure 1. Illustrated example of the encoding task (see text for details). Only a portion of the trigraph matrix is shown. 
letter "messages" displayed on the computer using a "trigraph" (printed on an index card) and a codebook containing a list of five-letter codes. The subject uses the first code from the codebook (e.g., EJQUD) to encode the first message displayed on the computer (e.g., BNGHT), the second code for the second message, and so on. The trigraph is a $26 \times 26$ symmetric matrix of letters, whose rows and columns are labeled $A$ to $Z$. To encode a message, the subject finds the row in the trigraph corresponding to the first letter of the message (e.g., B) and the column corresponding to the first letter of the code in the codebook (e.g., E). The letter in the cell of the trigraph is the encoded letter (e.g., U), which the subject types into the computer. The subject encodes the remaining letters of the message and finally hits the ENTER key to enter the entire encoded message. The computer then displays the next message for encoding.

The duration of the encoding task is determined by the experimenter. The program keeps track of the number of correctly and incorrectly encoded messages, as well as the number of letters (as distinct from messages) incorrectly encoded. As in the case of the vigilance task, data are computed for the beginning, the middle, and the final third of each session.

\section{Software Implementation}

Before the computers are distributed to the subjects, an initialization routine must be run. For the vigilance task, this routine generates a complete array of random digits in accordance with the parameters set by the experimenter. The sequence is different for each computer; however, only one sequence is generated per machine, and that sequence is used each time the vigilance task is run. Although it might be preferable to generate a new sequence for each run, this process is time-consuming even on a desktop microcomputer and introduces an unacceptable delay in the field. In order to vary the sequence of digits from run to run, the list of digits is divided into 10 blocks and the sequence of blocks randomized.

For the encoding task, initialization entails generating the trigraph matrix and the list of codes (identical to the list printed in the codebook), both of which are needed by the program to score the subjects' responses. The same list of codes can be used by every subject at each run, since the messages are randomly generated and differ each time.

The software uses an identification number supplied by the subject to index the data arrays. Thus, several subjects can be run on one machine. The size of RAM is sufficient to accommodate daily summary statistics from $6 \mathrm{sub}-$ jects for 10 days, assuming that each subject runs the vigilance and encoding tasks once a day.

The software optionally provides the subject feedback in the form of a partial listing of a session's results. A separate print routine exists for the experimenter to list all the data stored in the computer.

\section{FIELD STUDY}

Two groups of 18 U.S. Army Special Forces troops participated in a 30-day exercise designed to compare the effects of feeding a reduced-calorie ration and a standard ration. During the exercise, soldiers engaged in reconnaissance, surveillance, and electronic warfare missions as part of their regular training. In addition, soldiers were issued pocket computer systems (one computer per 2 subjects) with instructions to complete the vigilance and encoding tasks once each day. All troops received prior training in the use of the computers.

Every 7 days, the subjects assembled at a base camp for medical evaluations and other testing. At that time, the computers were collected, the data transferred, and the programs reinitialized.

Throughout the study, the pocket computer systems performed reliably, although not entirely without failure. Data from approximately $5 \%$ of the completed test sessions could not be retrieved, due in part to problems with computer hardware. ${ }^{2}$ The complete results of the study are described by Askew et al. (1987).

\section{CONCLUDING OBSERVATIONS}

Although the pocket computer system offers flexibility for cognitive testing under field situations, there are some potential limitations to this testing technique. Testing under uncontrolled field conditions introduces variables (e.g. , temperature, time of day, and potential distractions during testing) that will almost certainly increase the variability of the performance data relative to that obtained under controlled field or laboratory conditions. On the one hand, these external influences can be viewed as nuisance variables that would best be controlled. On the other hand, the increased variability accurately reflects the fluctuations in performance that occur in realistic conditions and may contain important information for the investigators. Further studies are needed to establish the sensitivity of cognitive tasks administered in this fashion.

\section{REFERENCES}

Askew, E. W., Munro, I., Sharp, M. A., Siegel, S., Popper, R., Rose, M. S., Hoyt, R. W., Martin, J. W., Reynolds, K., LieBerman, H. R., EnGell, D., Shaw, C. P. (1987). Nutritional status and physical and mental performance of special operations soldiers consuming the Ration, Lightweight, or the Meal, Ready-to-Eat military field ration during a 30-day field training exercise (Report No. T7-87). Natick, MA: U.S. Army Research Institute of Environmental Medicine.

BAKAN, P. (1959). Extraversion-introversion and improvement in an auditory vigilance task. British Journal of Psychology, 50, 325-332.

Bittner, A. C., Smith, M. G., Kennedy, R. S., Staley, C. F., HARBeson, M. M. (1985). Automated portable test (APT) system: Overview and prospects. Behavior Research Methods, instruments, \& Computers, 17, 217-221.

Davies, D. R, Parasuraman, R. (1982). The psychology of vigilance. New York: Academic Press. 
DRURY, C. G. (1987). Hand-held computers for ergonomics data collection. Applied Ergonomics, 18, 90-94.

GreEN, D. M., \&WETS, J. A. (1966). Signal detection theory and psychophysics. New York: Wiley.

Schlichting, C., WraY, D. (1986). Cognition: A program for the presentation of several tests of cognitive function using the HewlettPackard 85 computer. Behavior Research Methods, Instruments, \& Computers, 18, 65.

Wilkinson, R. T., \& Houghton, D. (1975). Portable four-choice reaction time test with magnetic tape memory. Behavior Research Methods and Instrumentation, 7, 441-446.

Wilkinson, R. T., \& Houghton, D. (1982). Field test of arousal: A portable reaction timer with data storage. Human Factors, 24, 487-493.

\section{NOTES}

1. BASIC program listings are available upon request from the first author.

2. Some of the computers used in the study were refurbished models and performed less reliably than the new ones.

(Manuscript received February 16, 1988; revision accepted for publication June 2,1988 .) 